\title{
Leadership in Principle
}

\author{
Uniting Nations to Recognize the Cultural \\ Value of Water
}

\author{
Veronica Strang
}

In 2016, the United Nations confronted alarming projections about impending water shortages worldwide, suggesting a potential 40 percent shortfall in water availability by 2030 (United Nations High Level Panel on Water 2018, 7). Concerns about water scarcity had been growing over the previous decade: the United Nations Development Programme suggested in its 2006 report that water use was rising at twice the rate of population growth and that a quarter of the world's population faced impending problems with water scarcity (UNDP 2006). By 2016, the scale of the problem had become painfully evident to many state governments and national and international NGOs. It was clearly a matter of increasing urgency to provide global leadership focused specifically on water. The UN therefore appointed a High Level Panel on Water to address these issues and to develop some new principles for water to underpin its recently established sustainability goals. Such panels are led by what the UN calls sherpas, underscoring the expectation that they will provide a lofty overview. The panel's remit was to encourage heads of state to develop more sustainable policies and practices in relation to water governance, management, and use, in particular by rethinking how water is valued. Moving beyond a largely economic or technical conversation required the panel to make greater use of the social sciences' and humanities' capacities to address the complex social and cultural issues that attend diverse evaluations of water.

This chapter examines that process and considers how such "top-down" endeavors might engender changes in policy and open up new ways of engaging with water, both among national leaders and at a grassroots level. It therefore engages with research exploring the relationships between local communities, major governmental and nongovernmental organizations, and international networks. 
It is now some time since anthropology began to "study up," as social anthropologist Laura Nader recommended, to consider the powerful organizations and wider networks with which local communities engage in negotiating water issues (1969). Much good ethnography has been written about organizations (Corsín Jiménez 2007; Garsten and Nyqvist 2015; Nash 1979) and on state bureaucracies (Herzfeld 1992). Fajardo's analysis of Malalos, Philippines, in this volume exemplifies the utility of this direction. There is also a range of work from within anthropology and development studies considering the nearly forty thousand NGOs to have emerged in recent decades. With varying degrees of criticism, analyses have considered the role of such organizations, and in particular international NGOs: as aid and development agencies, as mechanisms for the dissemination of neoliberal values, and as attempts to access markets and resources (Arce and Long 1999; Crewe and Axelby 2012; Escobar 2005; Lewis and Mosse 2006). Such work has highlighted the reality that all such organizations contain important social and professional networks that, via complex linkages, intersect dynamically at a variety of scales (Latour 2005; Scott 2000). In this volume, for example, Wescoat and Muhammad examine the importance of allowing cultural values to lead water policy, management, and systems conversations in the Indus River Basin.

In effect, in relation to water, as well as other global policy issues, NGO networks have generated national and international elites, empowered by political influence, access to resources, and technical or scientific expertise (Allen 2018; Lashaw, Vannier, and Sampson 2017). As private organizations, NGOs have highly varied aims and motivations. Their activities may be complementary to state efforts, but they may also displace state agencies (Leve and Karim 2001), or challenge state orthodoxies and act as catalysts for change and transformation (Korten 1990). They can enable the wider embedding of neoliberal ideologies or support challenges to dominant norms and countermovements. Thus, Tsing observes that, in some contexts, they have the potential to provide alternatives to state authority and promote environmental justice (2005). The Earth Law Centre and the Global Alliance, for example, are lobbying for environmental legislation aimed at improving nonhuman rights, including the rights of rivers and ecosystems. Other NGOs and networks are more concerned with conventional development goals. For instance, as an industry-based organization, Water UK aims to bring expertise from British water companies to support the provision of clean water and sanitation in countries where such current technologies for doing so are insufficient. But at the same time, in the decade following water privatization in Britain in 1989, some of its member companies were simultaneously (and very profitably) involved in offering expertise in water privatization to the governments of these nations. Many such privatizations have been extremely problematic, leading to major conflicts, and in the last decade there has been a 
countertrend towards reversions to state provision (Hoedeman et al. 2013; Kishimoto, Lobina, and Petitjean 2015).

In this complex global mix of governments and international organizations, the United Nations has a vital responsibility to try to bring diverse actors together. Established in 1945 as an intergovernmental organization, its first and foremost role, following the devastation of World War II, was to maintain peace and order between nations (Ghali 1992). Today the UN contains 193 member states, and its mission has expanded, logically, into areas that are vital to peace and order, such as international justice, human rights, health, and the conservation of cultural heritage. Its interests in health include long-standing concerns about the provision of clean water and sanitation, and there is strong recognition that health, social order, and stability also depend on water (and thus food) security. The UN's global efforts to address water issues have been assisted by a variety of UNESCO programs, such as the International Ecohydrology Programme, its extensive work on water and cultural heritage, and the establishment of the UNESCO-IHE Delft Institute. The UN's agenda for 2030, issued in September 2015, defined seventeen Sustainable Development Goals, and its more recent efforts to compose some new Principles for Water acknowledged the centrality of water in all of these.

In relation to water, as with other global policy issues, the UN has a range of formal and informal mechanisms for articulating its goals and bringing state and nonstate actors together. Its activities are iterative: consultation generates some agreement on ways forward, preliminary plans are set out in reports, further consultation follows, and the process is ongoing. At various junctures, agreement is reached between its members, and declarations, goals, and principles are formally established. Inevitably, the contributors to the conversations facilitated by the UN have varying degrees of power and influence, and there is a tendency for dominant ideologies, understandings, and discourses to prevail. Just as more powerful political actors tend to have the loudest voice in debates, so too do the more influential academic disciplines: thus, UN conversations about water have long been led by STEM disciplines and economics. However, this began to change in the 2ooos, with more input from the social sciences into the International Ecohydrology Programme, into UNESCO's work on water and cultural diversity (Johnston et al. 2012), and in the founding of the International Water History Association in 2001, which Faletti mentions in this volume. This involvement helped, in particular, to highlight the variations in people's relationships with water, and in the geopolitics of different national and cultural contexts.

Recent advances in digital technology have also widened the pool of potential participants in UN activities. For the first time in human history, it has become possible to conduct global conversations in real time, Skyping or Zooming in people who might otherwise find it difficult to make it to formal meetings. The virtual networks enabled by social media mean that many previously marginalized groups 
have greater capacity to speak for themselves and to each other (Miller et al. 2016). Some, such as Indigenous communities, have created their own international networks that have significantly increased their abilities to compare notes, to articulate their shared beliefs and values, and to be heard in global fora. Thus the panel's meetings in The Hague to compose the Principles for Water included-in person and via digital media - not only governmental, NGO, and economic advisers, but also a wider range of disciplinary experts and representatives from diverse cultural contexts.

The potential to encompass greater diversity is a mixed blessing for the UN. Different cultural and disciplinary perspectives certainly enhance debates. However, reconciling widely disparate beliefs and values adds to the challenges that the UN faces in reaching agreement on vital issues, such as deciding upon the Principles for Water that should be applied. There are clearly some gaps between the ideas and ways of thinking that have tended to dominate proceedings thus far, and the views of the more diverse subaltern groups that have recently entered the conversation.

Rather than foregrounding the implicit (and sometimes explicit) ideological and political conflicts inherent in this equation, the UN has framed these differences in terms of values. This is not an isolated effort: there is increasing recognition that values are central to debates about water. For example, the Vatican recently raised the issue of valuing water in broader terms as part of its mission (Tomasi 2017), and it is becoming clear that, while technical obstacles are real, it is the choices made about these that are critical. As Groenfeldt puts it:

Somehow we have gotten used to the idea that water management is a technical subject better left to the experts. . Water management is technical, but there are lots of value assumptions embedded in the technical choices. Moreover, the governance of water, the laws, policies, and institutions that set the context for water management, is anything but technical. Water governance is all about values. $(2013,3)$

An additional complexity for the UN (and in policy-making generally) is the diversity of views about what values are. In discourses relating to water, there is a considerable gulf between narrow technical or economic concepts of value, generally seen as a form of quantitative measurement, and more complex and largely qualitative social concepts of value. Cultural groups can have very different approaches to value: Indigenous communities in particular rarely conform to dominant notions that values are either "cultural" or "natural" (Agnoletti and Santoro 2015). They also tend to have more holistic concepts of value, integrated with multiple domains of their lives (Harmsworth, Awatere, and Robb 2016; Strang 1997). As Graeber observes, a comparison of diverse ways of approaching value and meaning-making can therefore be revolutionary, disrupting more reductive economist paradigms (2001). It is in bridging these gaps, between different ideas about value, that the theoretical frameworks and the cultural translation provided by the social sciences and the humanities is vital. 


\section{CREATING NEW PRINCIPLES FOR WATER}

With funding and administration from the World Bank, and led by the Netherlands, the UN's High Level Panel on Water commissioned a team of experts to write background papers that, by elucidating ideas about value, would provide the basis for widespread discussions between representatives from its member states and from major international water-related organizations. From this discussion they hoped to gain agreement on a formal set of principles. My small contribution to this very large conversation was, first, to respond to a request for a foundational paper on cultural and spiritual values relating to water and then, as it turned out, to assist the panel in discussing and writing the first draft of the Preamble and Principles.

As I discovered in working with UNESCO's water-related programs for a number of years, bringing social theory into this kind of forum contains significant challenges for scholars from the social sciences and humanities. This was particularly the case with the Ecohydrology Programme, whose Steering Group (until I was invited to join it) was entirely composed of hydrologists, engineers, and ecologists. Their preference, rather than engaging with social theory, was to employ what they called social hydrology: in essence, social science "reinvented" by engineers. Bringing real social theory into this context was uphill, but eventually a third element of social science was established, at least for as long as the Steering and Advisory Groups continued to include social scientists. But, as this implies, the ongoing participation of social science and humanities scholars is critical in such endeavors.

As Bille Larsen observes, ideas about culture are now broadening (2017), as are understandings of cultural heritage (Brumann 2017). However, the UN continues to divide "values" into three areas-"economic," "environmental," and "cultural and spiritual" - and to assume that these are somehow separate and not equally reflective of "cultural" beliefs and values. This is, of course, a reflection of dominant values in itself. The High Level Panel for Water team leaders accepted my point that all values, including those relating to economic and environmental issues, are intrinsically cultural, but observed that we would still have to work with-or, better still, try to shift-popular understandings of "culture" as some kind of separate domain.

Nevertheless, there are some advantages to the UN's conventional insistence on different categories of value, as they highlight the reality that short-term economic concerns tend to override more complex cultural beliefs and values that are focused on long-term sustainability. In producing a background paper for them, I therefore underlined the point that cultural and spiritual values permeate all human engagements with water, including those focused on economic or ecological concerns, as these too are formed by particular beliefs and understandings. When we describe values as being "cultural" or "spiritual" in nature, 
we generally mean the deeper, more complex values that hold societies together and that are sometimes subsumed by immediate pressures to meet material and economic needs.

Thus, there is some useful potential to discuss "cultural and spiritual" values as a way of critiquing unsustainable political and economic short-termism. This is urgently needed, as it is plain that most water policies and practices are focused heavily on responding to pressing exigencies, such as the provision of clean water and sanitation or the generation of hydroelectricity to enable economic growth. In doing so, while they may meet immediate social needs, such policies often externalize the costs to less powerful human communities, to future generations, and to nonhuman species. The dominance of short-term economic priorities is readily visible at a local level: the task for the UN is to make this dominance more visible at national and international levels, to the extent that questioning shortterm economic priorities becomes part of international debates and promotes the reform of national water policies. Key to driving these changes is the equal consideration of "cultural values" focused on the need to protect ecosystems, to uphold the rights and interests of nonhuman species, and to ensure their well-being (as well as that of future human generations).

A first step, therefore, was to highlight the reality that some "values" are given more weight than others, to underline their relationality, and to provide some definitional clarity. This entailed challenging centrally positioned scientific views that value means something quantitative. I therefore underlined to the panel that values are a way of articulating what we think is important and should be prioritized and protected. They compose individual and collective identities and define relationships between human groups and with the nonhuman world. While formal valuations tend to focus on reductive quantitative measures and may be material (e.g., pH measures) or monetary, these sit within a broader context of personal and societal values that are less readily condensed.

Understanding values therefore rests on three key points. First, we need to recognize that all values are relational, involving comparative judgments about what matters the most. Water management reflects decisions about priorities. It is also an exercise of power in which it is critical to consider whose values are being applied and whose interests (human and nonhuman) are-or are not-being met. Second, all values are ingrained: people are habituated into values through education, everyday practices and rituals, social approval or disapproval, and the representation of values in various media, as well as via social and material norms. Specialized contexts (such as particular industries) inculcate subcultural values. Regular engagement with a value-laden context literally inscribes values into the brain, wearing "pathways" to particular patterns of thinking. Third, while quantitative valuation methods seem to offer informed and transparent decisions, many of the most important "cultural" values are difficult and sometimes impossible to quantify. It is here that the social sciences and humanities can really broaden the 
discussion. Value assessment increasingly includes at least superficial qualitative data, but it remains challenging to articulate complex values, such as what heritage means to people, the aesthetic and spiritual experiences that water enables, or the many and diverse contributions to human and nonhuman well-being that ecosystems provide. To include complex values fully and transparently in water management and use, there is a need to make better use of qualitative evidence (such as that produced by ethnographic and historical research) and to employ analytic approaches from the social sciences and humanities.

Understanding that values are relational highlights the inherent tensions within concepts of sustainable development as they apply to water and to all material engagements. Illich has argued that the concept of sustainable development-as it is currently understood-is fundamentally an oxymoron, since conventional visions of development assume continual economic growth and expansion (1999). Thus, values are not merely relative, they can be irreconcilable. The UN Sustainable Development Goals exemplify this problem. Goal 6: "Ensure access to water and sanitation for all." Goal 7: "Ensure access to affordable, reliable, sustainable and modern energy for all." Goal 13: "Take urgent actions to combat climate change and its impacts." Goal 14: "Conserve and sustainably use the oceans, seas and marine resources." These worthy goals rest on critical values about health and social and ecological justice, but even with greater efficiencies they are unlikely to be met as long as concepts of growth and development remain wedded to each other. Unless artificially increased by unsustainable uses of energy and resources, freshwater resources are finite: all water uses represent value choices that are ultimately sustainable... or not.

As illustrated by the photograph of the salination created by producing profitable but soil-damaging cotton in arid regions (figure 9.1), it is inevitably easier to prioritize short-term gains over long-term losses, particularly if the latter accrue to other groups, future generations, or nonhuman beings. But such shorttermism is literally costing the Earth. Water is the perfect mirror of relations of power within and between societies and, I would suggest, equally reflects relations between human groups and nonhuman and material worlds. From a local to global scale, inequalities in human and nonhuman relations are manifested in all of the everyday choices made about water management and use. Societal values are writ large, in particular, in choices about infrastructure, which manifest priorities on a grand scale and over long periods of time (Strang 2020).

Locally, nationally and globally, just as the interests of less powerful human communities are persistently overridden, so too are the needs and interests of nonhuman species. In the last few centuries, and most particularly in the last century, human population expansion, along with ever-increasing levels of habitat destruction and water redirection to meet human interests, has led not only to major displacements of human communities, but also to a massive-and still rapidly accelerating - spike in species extinctions, increasing the "normal" rates of 


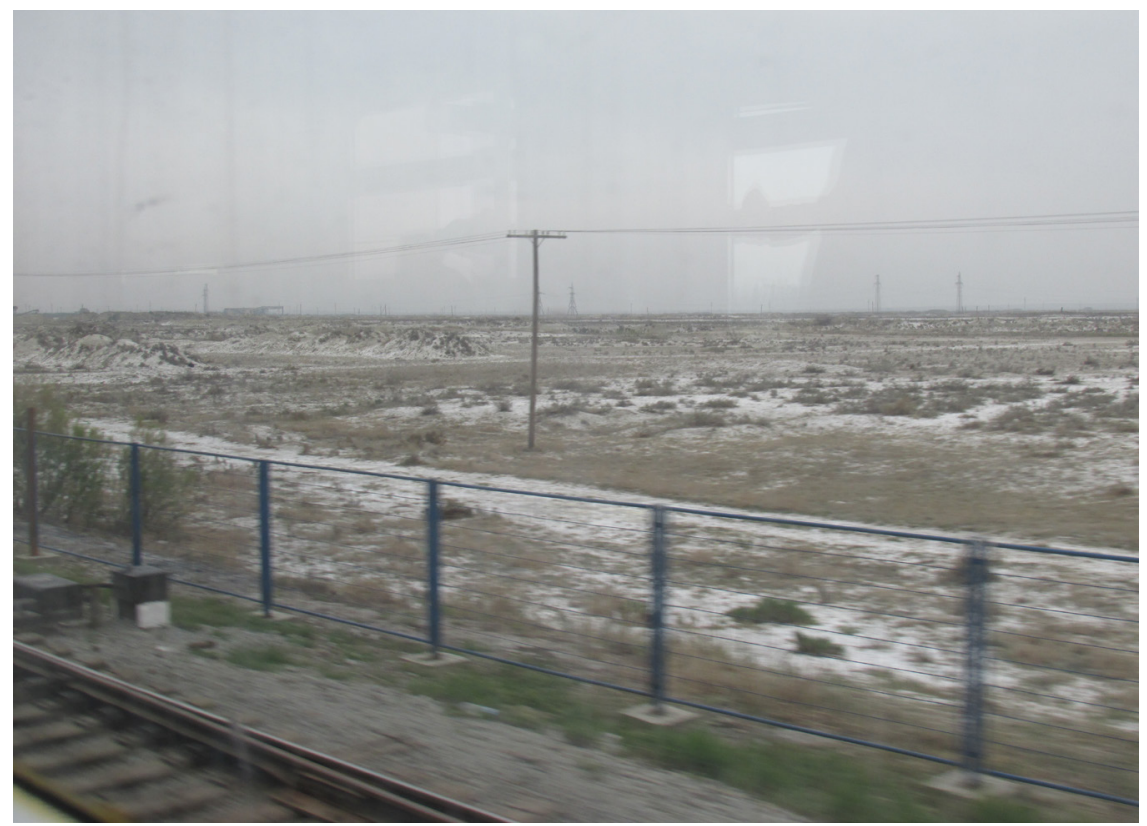

FIGURE 9.1. Salinated landscape in Uzbekistan, where irrigation to produce cotton has raised salts to the surface, rendering the soil infertile. Photo courtesy Veronica Strang.

species extinction by about 10,00o percent and, in the last forty years, reducing the populations of nonhuman species by 60 percent (WWF 2018).

Meanwhile, as noted previously, 40 percent of the world's population is affected by water scarcity, and the UN anticipates a much larger shortfall between supply and demand by 2030 (United Nations High Level Panel on Water 2018, 7). Rising populations will need (on top of the current 70 percent used) 15 percent more freshwater for irrigation and still more to provide sufficient energy supplies (World Bank n.d.). Such demands will push governments to continue to redirect water into agriculture and other forms of economic production, and to prioritize the interests of the most powerful groups. In this economically focused, growthoriented equation, it is easy to see why primary producers around the world are under constant pressure to expand and intensify their activities further. A farmer might aspire to be a local "guardian of the land" but, under external economic pressures, may sacrifice water quality by using fertilizers to intensify crop production. As Australian farmers often say, "it is hard to be green when you're in the red."

\section{UNITING NATIONS AROUND WATER}

How can we hope to achieve more genuinely sustainable human engagements with water in which "development" comes to be about doing it better rather than doing it more? How do we achieve the international and intercultural cooperation 
needed to solve the problems created by untrammeled growth in human numbers and in human activities?

The United Nations' primary role is to enable inclusive and constructive conversations between societies. Such international bodies are inevitably cumbersome, and deeply hampered by myriad political agendas and people pulling in different directions. But global cooperation depends absolutely on human societies having just such conversations, and, as I noted at the outset, we are now living, uniquely, in an age when it is technologically feasible to do so in real time. It is now possible to go to The Hague to discuss water issues with experts from around the world, and to have a much wider tranche of them participate via virtual means in the conversation. It is possible to write in collaboration with distant colleagues and to circulate material for immediate discussion with high numbers of international participants. So we have the technology; the question is, do we have sufficient will and patience to bring local perspectives into a larger conversational forum and to persist with negotiations that will lead to real change?

Although UN networks constitute a community of sorts, working at this abstract international level is a very different kind of experience for social scientists and humanities scholars. For anthropologists, it raises some challenging questions about how to translate local, ethnographically based understandings of human behavior into highly generalized discussions and takes us into key debates about the comparative nature of our discipline and the extent to which ethnographic findings can be scaled up into meta-discourses to discuss broader human questions. Similar questions can be raised in relation to historical or literary comparison. In fact, in dealing with water issues, this transition is not as difficult as it may seem. This is partly because water itself provides a medium through which it is not only possible but necessary to think across cultural and historical boundaries. Its material properties and behaviors carry one's thinking up (and down) through the various scales and systems through which water flows. In this sense, "thinking with water" provides a useful opportunity to consider how all disciplinary areas might address issues of scale.

In seeking to understand people's relationships with water, I have spent many years, in various parts of the world, meandering up and down river catchments with Indigenous leaders, farmers, industrial water users, recreational and domestic water users, and the public and private companies responsible for managing water flows and treating and delivering water. In accord with their particular cultural and geographic contexts and their specific activities, each of these groups has its own unique ways of thinking about, engaging with, and valuing water. Their different engagements with water often lead to conflicts that are intrinsically about values.

For example, in countries such as Australia and the United States, Indigenous communities, local catchment groups, and recreational water users often express deep anxieties about the effects of mining activities on water quality. In North Queensland, where gold extraction relies on the use of cyanide, riparian water users are concerned about how such poisons leach from storage dams into local 


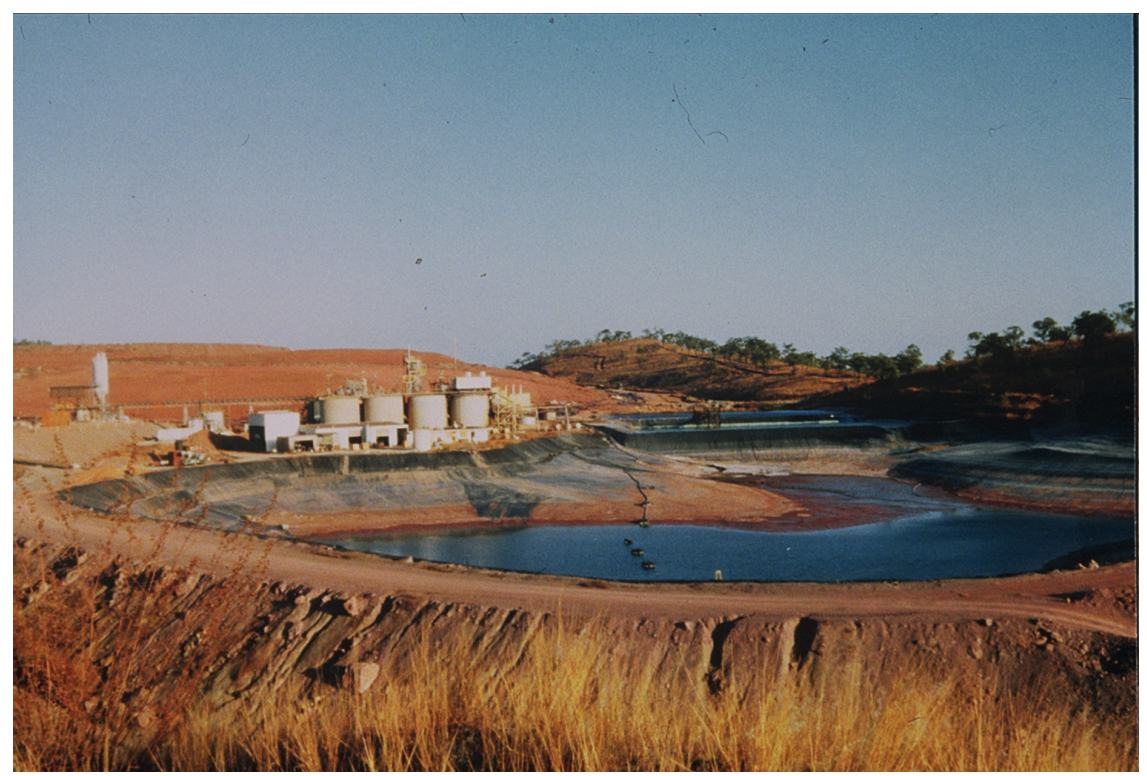

FIGURE 9.2. Tailings dam at Red Dome gold mine, Queensland. Photo courtesy Veronica Strang.

water courses (figure 9.2). There is also rising conflict about the effects of overabstraction on local ecosystems, and downstream farmers rail against the effects of the redirection of water by upstream irrigators.

But, because water flows through everything, such local conflicts are replicated at regional, national, and international levels. Social justice organizations protest against the enclosure and privatization of water, and political factions pull in different directions on issues of ownership and control. Conservation organizations criticize national and international policies that fail to protect the environment. Tiny hydro-squabbles about abstraction from local wells and aquifers, or over the direction of small streams, are echoed in major transboundary river conflicts.

Water is therefore very useful for thinking upwards-or enabling us, as Nader suggested, to "study up," both in terms of understanding wider contexts of governance and power and in thinking about the larger-scale social and ecological dynamics in which local water engagements are nested. All of the differences in values relating to water that emerge at a local level flow upwards into largerscale debates about water policy. How should water be governed, and by whom? Which-and whose-interests should be prioritized?

In working with the UN, the key challenge was to scale up-to articulate cultural and spiritual values in relation to water in a way that would be meaningful not only at different scales, but also in highly diverse cultural contexts. Fortunately, water is so central an element in every domain of human life that, while all 
engagements with water are unique to their particular cultural and subcultural contexts, water also holds powerful cross-cultural meanings that recur in each of these, albeit manifested in specifically local forms. It is an area in which it is unusually easy to bridge different cultural perspectives. With a view to supporting a shared conversation about values, I therefore drew on earlier ethnographic research to pull out some core themes of meaning around which important cultural values about water typically coalesce.

\section{Water as Life}

The overriding value in relation to water recognizes its essential role in hydrating and thus supporting life and health in all biological organisms. Landscapes are enlivened by water, and no ecosystem can function without it. The concept of water as a source of life is central to creation stories-for example, by Christianity's Genesis, in which God forms the world out of watery chaos; by the emergence of the Mayan world from primal seas on the back of the great water deity Itzam $\mathrm{Na}$; and by the Aboriginal Rainbow Serpent in Australia-an ancestral personification of water from which all life emerges. It can be seen, for that matter, in a contemporary scientific view that, having simmered in the oceans' depths for nearly four billion years, life on earth emerged from the water and "became" the species of today.

These foundational meanings and values continue to flow into everyday engagements with and conflicts over water, such as the Standing Rock controversy in the United States, where the Dakota Sioux, aided by a range of like-minded groups, have stressed that "water is life." A universal understanding that all living kinds-human and nonhuman-depend on water underpins long-standing ideas about water as a common good, and it places it centrally in debates about human and nonhuman rights, and social and ecological justice (Strang 2016a).

\section{Water and Connection}

At the most basic molecular level, water molecules have a particular capacity to bind with and thus carry other materials. Where this is most important in terms of meaning and value is that it is plain that water flows through and connects all biological organisms with each other. As McMenamin and McMenamin have pointed out, when terrestrial species crawled out of the oceans, they brought the sea with them, retaining a common organic dependence upon salt and water which the McMenamins describe as a "hypersea" (1994). And the flow of water through plants and animals links them to the material world, composing hydrologically and conceptually linked systems.

Like other aspects of water, this connectivity holds true at every scale. Water moves from cell to cell, irrigating organisms; soils, plants, and animals necessarily ingest or absorb water, integrating it into physical systems; groundwaters form invisible links beneath places; rivers join communities along their courses in a 
series of upstream and downstream relations; water supply systems connect houses and businesses within cities; and water infrastructures move water between rural and urban areas. At a planetary scale, oceans serve both to separate and connect continents. And people are well aware that they live in concert with planetary streams of hydrological movements.

Cultural values about the centrality of water as a connective substance emerge in multiple domains. We can see them in religious practices in which water is used ritually to symbolize social and spiritual connection. They surface in discourses about the meaning and value of blood connections. Blood may be "thicker than water," but it is largely composed of it, enabling many important ideas about fluid "ties" between kin and intergenerational flows of identity. Fluid interconnections also feature strongly in scientific narratives. For example, the concept of "an ecosystem" is fundamentally a vision of material flows connected by water. At a planetary scale, Vernadsky's notion of the "biosphere" conceptually and materially links all living kinds.

\section{Water and Spiritual Being}

As the creative "substance of life," water is often seen as an analogue of human spiritual and social identity, carrying people into and out of corporeal being. This coheres with beliefs that life entails "becoming" material-i.e., embodied- and sentient, while death brings a loss of material form, consciousness, and memory. Just as primal waters generate whole worlds in stories of cosmogenesis, water is often seen as a creative well for human lives and as the medium through which persons are returned to the fluidity of nonbeing. In Classical underworlds, therefore, the rivers Styx and Lethe involve departing and "forgetting."

In some cultural contexts, human and nonhuman life cycles are tied conceptually to hydrological cycles: to visions of life emerging from waters within the land. In Australia, for example, the Rainbow Serpent illustrates just such a hydro-theological cycle. Held within water places in the landscape, it generates human spirits, which then "jump up" to enervate the fetus in a woman's womb. This also illustrates a powerful idea about belonging: a belief that the person is "made of" the substance of that place and retains an inalienable social and material connection with it. As well as locating individuals spatially, this defines their place in a network of kin and their collective rights to clan estates. Upon death, the person's spirit must be ritually "sung back" to its place of origin, to be reunited with (dissolved back into) the Rainbow Serpent being. Such powerful beliefs underpin contemporary ideas about identity and cultural heritage, and understandings that societies are intimatelyliterally substantially - connected to the places they inhabit.

As well as generating human beings, the Rainbow Serpent is venerated as the source of all living kinds. Similar ideas are evident in the "rain shrines" found in many areas of Africa, which celebrate rainbow serpent beings connecting creatively with earth deities. They are visible in the rain-making rituals of native 
peoples in America and Canada and in their adherence to the notion of sacred, generative landscapes that has given such impetus to the recent protests about the Dakota pipeline.

Such meanings and values also explain why many cultural traditions contain ideas about "living water" or "holy water": water that contains spiritual essence or which has the power to bless, to cleanse and heal, to enlighten, and to enable transitions through life (and death). Concepts of spiritual and social belonging are intertwined, and water rituals express community, whether through the baptism of strangers, so that they will be recognized by sentient nature beings in Aboriginal cultural landscapes, or through the baptism that incorporates newcomers into Christian congregations.

A related idea imagines water as a source of enlightenment and spiritual wisdom. Biblical and Qur'anic literature provides plentiful images of water as a stream of knowledge or fons sapientae, and there are many historical and contemporary cultural traditions in which people seek wisdom from wise ancestral water beings via rituals of engagement with water. Returning to Australia, for example, the Rainbow Serpent is seen as the source of all knowledge, and-in Cape Yorksecret sacred knowledge is gained through a ritual of immersion, described as "passing through the rainbow."

In a world where most people continue to hold religious beliefs of one kind or another, such ideas still exert a powerful influence on cultural values relating to water. Beliefs about water as the substance of the spirit affirm ideas about water as public good, strengthen views on ownership and privatization, and create extreme responses to issues affecting water quality.

Beliefs about water and the spirit have also segued, unproblematically, into secular ideas about water as a focus for enlightening meditation and experiences of belonging and "oneness" (or in Confucian terms "harmony") with nature. This connects with recreational water use and people's sensory and aesthetic experiences of engaging with water: the fun of playing with water, the restfulness of immersion and weightlessness, or the pleasure of gazing at water. These are all powerful sensory and affective experiences, and therefore generate real emotions-which, as well as creating demands for access to waterways, reservoirs, etc., also flow into values relating to conservation, anxieties about pollution, and so forth.

\section{Water and Agency}

No form of production is possible without water. It is fundamental to human capacities to act upon the world, to make things, to grow crops and maintain livestockin other words, to gain social and economic capital. Water is equally vital to the reproductive capacities of nonhuman species and ecosystems. Human instrumentality in managing water invariably involves choices about which groups' and/or which species' generative capacities are most valuable. This highlights the most critical issue in water management: the tension between human desires to redirect 
water flows to support their own productive activities and a growing recognition that practices depriving ecosystems of sufficient flow to reproduce themselves are unsustainable and lacking in ecological justice.

Water also has its own agentive powers-a major thread in this book-and its actions upon the material world are not confined to hydrating biological life forms. Oceans stabilize planetary systems. The movements of water shape landscapes, carving valleys and lakes and forming wetland areas. Water flows irrigate, carry fertilizing sediments, and remove waste matter. Water enables the movement of people and goods, and of aquatic species. Its physical forces have long been harnessed to produce energy, via ancient water mills and now through hydropower. The potential of water to produce "work" has long been part of the active process through which societies reproduce themselves.

The value of water therefore encompasses a range of direct and indirect agentive capacities. This reality flows into debates about irrigation and issues about overabstraction and salination, into upstream-downstream conflicts, into disagreements about water charges and allocations, into dissent about environmental flows, and into concerns about controlling floods and droughts.

\section{Water as Order}

Water flows literally sustain social, economic, and political order. The movements of water also provide a compelling metaphor about other "flows": economic flows involving "circulations" of resources, "out-of-control" floods or droughts in the market, and notions of "trickling down." It provides a way of thinking about intergenerational flows of knowledge and belief, as well as the flooding, leaking, or seeping of ideas and information from one group to another. It is used to manifest ideas about identity and the circulation of people within and between groups and between geographic regions.

Thus, each of the various meanings of water contains a notion of "orderly" (right) and "disorderly" (wrong) flows, expressed through powerful ideas about purity and pollution. Concepts of pollution are universal, being concerned with "matter out of place." Out-of-control flows of water provide a metaphor for disorder, giving a powerful emotive dimension to floods that contaminate domestic spaces with "foul water" or to anxieties about mine leachate. Drowning metaphors articulate ideas about being "overwhelmed" by emotion. They are employed to describe foreigners "swamping" local social identities or the "pollution" of unwelcome ideas. Images of drought describe not only failing crops and dying cattle, but also markets "drying up," emotional deserts, and the "dust to dust" desiccation of aging.

These metaphorical images of water contain substantial symbolic meaning, and this leads to quite different ideas about what is deemed to be orderly. For environmental activists, order generally means maintaining sufficient ecological flows, while for business interests order may mean ensuring more redirection of water into productive activities. Anxieties about order are also evident in responses to disorderly flows, such as floods and droughts, and may be manifested 
in demands for flood defenses, water storage, more water security, desalination plants, and such. And fears about the disorder of pollution flow into debates about water quality regulation, environmental legislation, and penalties for polluters.

\section{Water as Health}

Long-standing recognition about the importance of water in relation to human health is illustrated by the earliest recorded libations, intended to "revive" (i.e., rehydrate) the mummified bodies of Egyptian pharaohs. They can be seen in the votive offerings by Celtic tribes and Romans to the water deities of healing springs and wells and in the historical reformation of these sites as "holy wells," expressing the miraculous powers of saints and prophets. Zamzam, a sacred well near the Ka'ba in Mecca, has been the focus of pilgrimages for millennia, and ninthcentury scholar Ibn al-Faqih noted that its waters provide "a remedy for anyone who suffers."

In a more secular age, many European wells became spas offering "healing waters" and providing careful scientific lists of their health-enhancing minerals. Today, ideas about water as a source of health and vitality are readily visible in the marketing of bottled spring water and in the images of babies gamboling underwater or spouting geysers that persuade people to pay well over the odds for such water's "reviving" qualities. This also costs the earth, as thirteen liters of freshwater are required just to make the bottle.

So, it is clear that, despite changes in form, the notion of "living" health-giving water has persisted tenaciously across time and across cultures. Recognition of water's centrality in maintaining human and nonhuman health is evident in efforts to provide all human communities with clean water, for example in the UN's goal "to ensure access to safe water sources and sanitation." It surfaces in medical advice about drinking sufficient water, and in regulations designed to protect water quality both for drinking water and to sustain the health of ecosystems. It is foundational to debates about water and environmental management.

\section{Water as Wealth}

In English, "wealth" and "health" are etymologically and conceptually related, both words connoting "wellness" as being "hale" or "whole." Water enables individual bodies, families, communities, and nations to maintain social and physical integrity and well-being. To hold water-with a dam, in a lake, through owning water allocations or shares in a water company-is to hold wealth. This is readily demonstrated in the high status of water features: spurting generative fountains that grace national monuments, parks, mansions, and private gardens.

The centrality of water to all forms of wealth creation is starkly illustrated in images of wealth and poverty. The rich inhabit lush green spaces, have hot and cold running water, and wealth signifiers such as swimming pools and waterfront homes. The poor are marginalized in deserts or gardenless slums: without proper or clean water supplies, they must trek for miles toting water containers or take 
their washing down to the river. Imagined paradises and utopias are well-watered, green, and fertile. Hell involves fetid slime, blasted deserts, or fire.

The underlying meanings of water as wealth provide a broader context for the specifically economic valuations of water that generally dominate discourses relating to water management and use. What may seem like entirely pragmatic measurements of water allocations, crop yields, and contribution to GDP are nested within much more complex cultural values about individual and collective abilities to harness water's generative power and to be socially and economically productive. Notions of "wealthiness" are collectively expressed in notions of the common good or "the Commonwealth." The conflation of water and wealth lends intensity to debates about ownership, control, and access to water, and these debates provide a context for conflicts over governance, legislation, water supply, charges for water, and choices about priorities for water use.

Water is also central to conflicts about "growing the economy." The "growth is good" mantra obscures the reality that this involves important value choices. The growth of some things, or the promotion of particular interests, may be at the expense of others. Water redirected into hydropower may benefit national economies but prevent the flourishing of local communities or ecosystems. Irrigation schemes-as illustrated in areas such as the Murray Darling Basin or the Colorado River-may promote the growth of "high value" crops such as cotton or rice, but do so at the expense of native vegetation and biodiversity.

\section{Water as Power}

The control of water is fundamental to political power and to the sovereignty of nations, and arrangements around the ownership and control of water directly reflect the realities of power relations within societies. This has been most famously illustrated by Wittfogel's account of the relationship between the development of vast canal systems in China and the power of imperial dynasties (1957). But it is also readily evident in India, South Korea, and many other parts of the world, where major dams and irrigation schemes remain entangled with aspirations for nationhood, and with the power of social and political institutions. This also applies within states: California continues to experience internal "water wars," and in Australia there are some lively upstream and downstream controversies between Queensland and NSW about flows across the border into the Murray Darling Basin (figure 9.3).

The notorious case of Cubbie Station, which captures about a quarter of the water that would otherwise flow across the Queensland border into the Darling River, also reminds us that, in a global economy, water privatization has begun to shift control from governments to transnational corporations. This important trend gives increasing control over freshwater flows to institutions that are socially and physically detached from local communities and their environments. Such "disembedding," as Polanyi called it (1957), raises major issues around ownership 


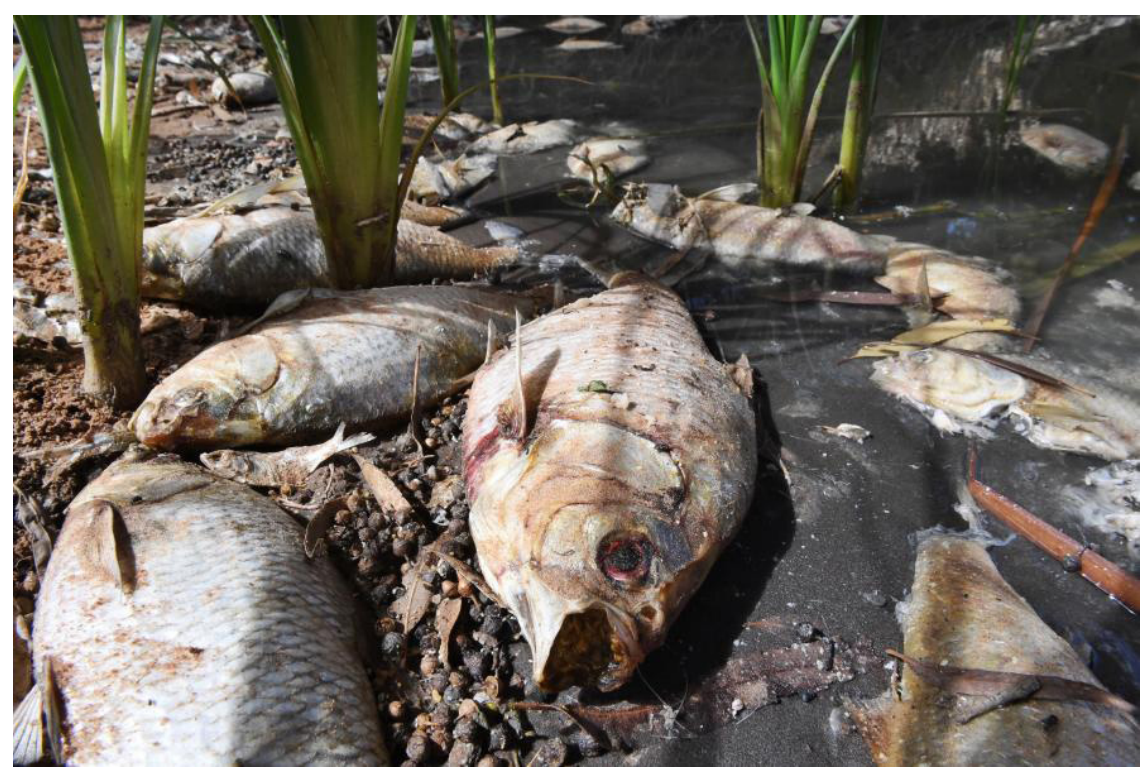

FIGURE 9.3. In 2019 over a million fish died in the Murray-Darling Basin because of the algal blooms and loss of oxygen caused by insufficient water flows. Photo Wikimedia Commons.

and about democracy itself. As I have noted elsewhere (Strang 2016b), governments can only govern effectively to the extent that they can control essential resources and ensure water security. Social scientists should be asking pointed questions about whether and how governments can do so when land and water are owned by transnational corporations with no local accountability.

Forms of water ownership range from collective (common property regimes or national ownership) to privatized water supply companies and water markets. Attempts to govern the latter are expressed by regulatory regimes aiming to protect the rights and interests of people and environments, but there are major variations in regulatory capacities to meet these aims, and they are rarely adequate to the task.

Each form of ownership and regulation empowers or disempowers particular groups and expresses particular values. This connects directly with the extent to which water is regarded as a common good. Founded on moral questions about rights to the substance of life, access, and equity, the concept of water as a common good is central to historical and contemporary conflicts over water, whether at an international or local scale. It appears in historical accounts of negotiations about water releases between mills along medieval waterways, just as it does in contemporary discussions about transboundary flows on the River Jordan, or in every hydro-squabble about water allocations.

Power via the ability to direct water is not confined to governments, NGOs, and corporations or even to large-scale institutions. Scientists and conservation 
organizations participate in decisions about waterways through the application of their expertise. Community river management groups act directly to protect the health of their local waterways. Farmers' direction of water flows enables them to produce life's necessities and sustain their own and wider communities, and this role in feeding the world, in managing the land, is intrinsic to their subcultural identity, just as washing ore to produce gold or using water to make industrial products underpins the identity of miners and manufacturers. Such positive values are echoed by water engineers in the United Kingdom, who recall the heady days before privatization of being the "heroes" empowered to deliver water to the domestic tap. But it is also essential to note that there are major asymmetries in power relations too, and that some groups-such as Indigenous communities, ethnic minorities, women, and the poor-continue to struggle to participate in decisions about water, within nations and internationally.

How water is controlled and distributed is therefore, always, a direct reflection of social and political relationships, not only between humans but also between humans and other species. In this sense, decisions about water flows-and about whose human/nonhuman needs and interests are met-are immediately expressive of societal values about the environment.

\section{Water and Cultural Heritage}

The UN is paying increasing attention to the interconnections between water and cultural heritage. It is clear that water flows alongside both tangible and intangible cultural heritage. It is central to all societies' processes of production and reproduction-social, economic, political, and spiritual-and to the dynamic composition of cultural land and waterscapes. While there are thousands of important "world heritage" sites, these are not merely remnants of historical activities: they are a living part of cultural engagement with the material environment that reproduces particular lifeways. It is for this reason that in composing a Water Framework Directive in 2000, the first point articulated by the European Union was that "water is not a commercial product like any other but, rather a heritage which must be protected, defended and treated as such."

It is relatively easy to see why successive generations of farmers develop attachments to the land they have irrigated, and to the soils they have nurtured and made productive. In Australia, the outback "battlers" who have built up their farms over generations are central to Australian history and cultural heritage, and one might find similar narratives in many other histories of settlement. Yet in industrial societies farms are often alienable properties, and it is not unusual for farmers to sell up and move on. Still, nations continue to valorize this cultural history, and this is readily evident in political debates and in art, literature, and other media.

Cultural heritage is central for any group, but it is perhaps particularly important for communities who constitute ethnic or cultural minorities and who are 
trying to maintain traditional lifeways in larger societies. Cultural heritage carries quite different meanings and values for long-term place-based societies, such as Indigenous Australians and First Nation peoples, whose activities are mediated by permanent relationships with sentient land and waterscapes. In such contexts, cultural and spiritual values relating to water run deeper. To understand these close affective relationships between people and places, we therefore need to think more deeply and be willing to learn from very different cultural perspectives.

The centrality of water in relation to cultural heritage is apparent in every debate about how water should be owned, used, and controlled. It is readily visible in the concerns of small rural communities facing major upstream irrigation corporations. It is intrinsic to every land claim by Indigenous communities. It can be seen in the responses that are generated by every proposed development scheme.

\section{Articulating Cultural Values}

Another question the UN asked me to address was: how can values relating to water be articulated? Methodologically, it is possible to skate over the surface with surveys, for example by ranking people's concerns about waterways or their "willingness to pay" (WTP) for various measures, but deeper cultural values are not readily quantified. Social scientists and humanities scholars bring to the table robust qualitative methods that can make more complex values visible and comprehensible. Making use of archaeological and historical research allows us to compare relationships with water over time; and ethnographic research methods from anthropology (interviews and long-term participant observation) can create a detailed picture of diverse beliefs and values relating to water, and the everyday practices through which these are expressed and maintained.

As well as examining everyday practices, it is also useful to consider the use of water in religious and secular rituals. A nice example of the latter is provided by the Splash! Festival in Queensland, in which communities bring vessels of water from local waterways and pour these into a shared vessel to articulate how local waterways connect them to each other (figure 9.4). No major dam or irrigation scheme opens without rituals celebrating its capacity to control the power of water, and no spouting fountain, displaying the mana of a town or state or nation, is switched on without public ceremony and the participation of suitable dignitaries. These things are not difficult for social scientists to explicate.

However, the use of qualitative methods raises several related questions. What kinds of outputs are needed to communicate complex cultural values, and how can we ensure that these are incorporated into decision-making processes and given sufficient weight? Decision-making processes are currently heavily reliant upon economic models and reductive methods of presenting information in largely quantitative form. This is also indicative of the dominance of the values promoted by economic actors: keeping discussions focused on quantitative measures maintains 


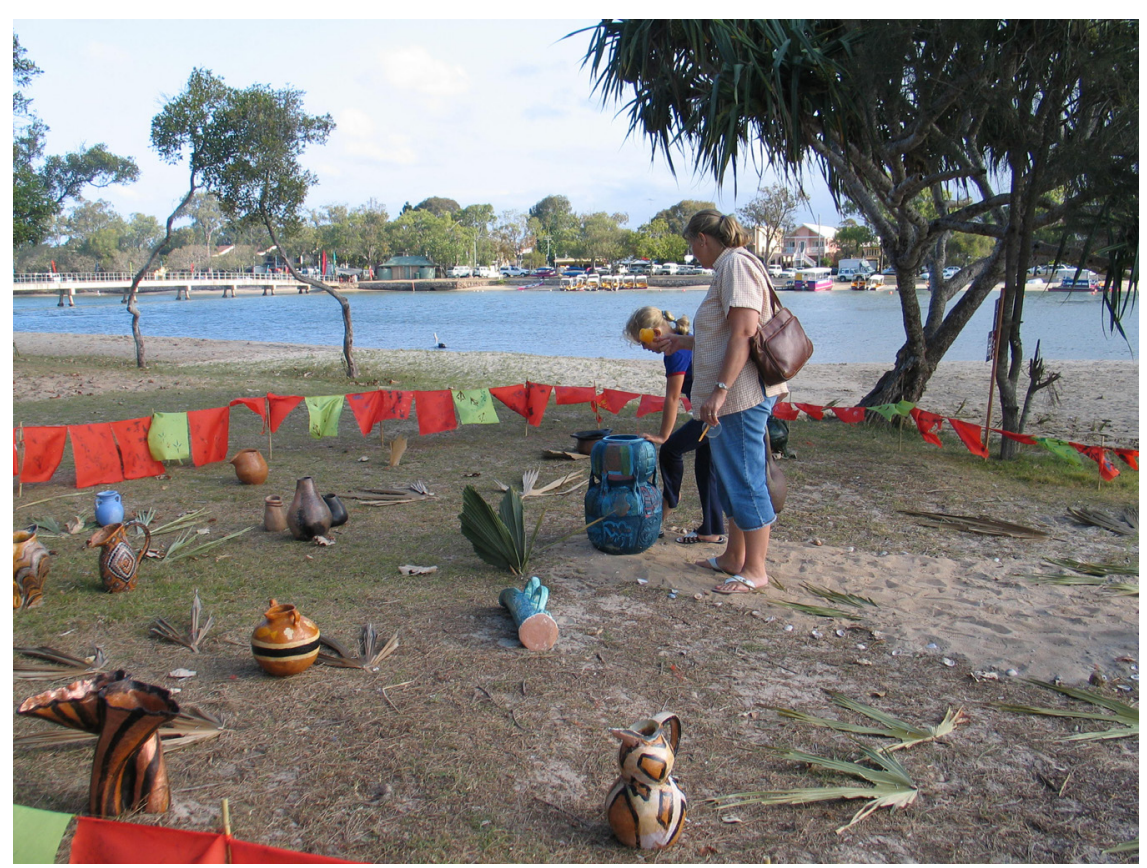

FIGURE 9.4. Splash! Festival water ritual in Maroochydore, Queensland. Photo courtesy Veronica Strang.

the primacy of their concerns. Introducing more qualitative material therefore meets resistance, not only from busy policy makers keen to have highly condensed information, but also from those for whom a reliance upon reductive discursive forms serves to exclude issues that might conflict with their particular interests.

Will giving more equality-and higher visibility—to cultural values mean that deeper concerns are consistently and equally reflected in water management decisions? It is not useful to valorize clean water for ecological or moral reasons on the one hand, if permission is given to money-saving polluting activities on the other. Different government agencies may be said to promote particulareconomic, environmental, and cultural-domains of value. Their relative influence and resourcing illustrates the point made at the beginning of this chapter: values are relational, and debates are fundamentally about which-and whosevalues matter the most. Realpolitik ensures that priority is generally given to short-term exigencies: the meeting of basic needs and the promotion of economic growth. The extent to which such priorities are ameliorated by longer-term thinking depends upon the political climate. Thus, when über right-wing politicians and climate change deniers have a free hand, it is more or less inevitable that funding cuts will be imposed upon environmental agencies or that environmental regulations will be relaxed. 
As this implies, what differentiates key values the most is whether they focus on immediate or long-term interests, on the interests of a few people or of all, and whether they encompass nonhuman needs and interests. Good leadership deals with exigencies but also considers the wider view and the longer term. It encompasses the well-being of all living kinds, both for moral reasons and because it recognizes the complex interdependencies that connect humans, nonhumans, and the material world. In this sense, the "common good" of water represents the wider common good of collective sustainability.

In my work with the UN, I have therefore tried to promote the idea that cultural and spiritual values are the deeper values of societies. Such values look beyond short-term social and economic needs to consider future generations and future worlds. They support more conservative use of resources and higher levels of protection for less powerful human and nonhuman populations. They have the potential to counterbalance values focused on short-term economic gains and to question assumptions about "growth." Making cultural and spiritual values explicit, giving them sufficient weight, and including them fully in debates about water use and management is therefore a matter of urgency. They provide the holistic, long-term view that is needed to shift decision-making towards more sustainable water policies and practices. I proposed several key principles that might be adopted:

Principle 1. Recognize and respect cultural beliefs and values and cultural heritage relating to water.

Principle 2. Fully include and give equity to diverse cultural and spiritual values, and their proponents, in debates and decisions relating to water policy and practice.

Principle 3. Prioritize cultural values and practices that promote social and ecological justice and protect the health of all human and nonhuman beings.

Having submitted the background paper and participated in a workshop in The Hague, I was invited to join the core writing team and to help draft the Preamble and Principles that would initiate a wider international conversation. The group wrote a strong draft, knowing that, as with all sensitive political matters that require consensus from diverse groups, any contentious points are likely to be diluted to almost homeopathic levels during the consultation process.

Following wider international conversations over the next few months, a set of agreed Principles emerged as part of the High Level Panel's outcome report in March 2018. In the first instance, the report reaffirmed its allegiance to quantitative data, observing:

The adage "you can't manage what you can't measure" is particularly true for water. Information about water quantity, quality, distribution, access, risks, and use is essential for effective decision-making, whether by businesses managing a production process, rural communities managing a well or basin authorities managing a flood. (United Nations High Level Panel on Water 2018, 16) 
However, the report also linked the issue of water to the range of UN Sustainable Development Goals and stressed that "Societies need to value the water they havein all its social, cultural, economic, and environmental dimensions" $(2018,13)$. It articulated the following principles:

\section{Recognize and Embrace Water's Multiple Values}

1. Identify and take into account the multiple and diverse values of water to different groups and interests in all decisions affecting water.

There are deep interconnections between human needs, social and economic well-being, spiritual beliefs, and the viability of ecosystems that need to be considered.

\section{Reconcile Values and Build Trust}

2. Conduct all processes to reconcile values in ways that are equitable, transparent, and inclusive.

Trade-offs will be inevitable, especially when water is scarce, and these call for sharing benefits amongst all those affected. Inaction may also have costs that involve steeper trade-offs. These processes need to be adaptive in the face of local and global changes.

\section{Protect the Sources}

3. Value, manage, and protect all sources of water, including watersheds, rivers, aquifers, associated ecosystems, and used water flows for current and future generations.

There is growing urgency to protect sources, control and prevent pollution, and address other pressures across multiple scales.

\section{Educate to Empower}

4. Promote education and public awareness about the intrinsic value of water and its essential role in all aspects of life.

This will enable broader participation, water-wise decisions and sustainable practices in areas such as spatial planning, development of infrastructure, city management, industrial development, farming, protection of ecosystems and domestic use.

\section{Invest and Innovate}

5. Ensure adequate investment in institutions, infrastructure, information, and innovation to realize the many different benefits derived from water and reduce risks.

This requires concerted action and institutional coherence. It should harness new ideas, tools, and solutions while drawing on existing and Indigenous knowledge and practices in ways that nurture the innovative leaders of tomorrow. (2018: 17) 
It will be evident from the finalized Principles that there was considerable compromise in language and priorities during the consultation process. Stronger points, for example about subaltern and nonhuman rights, were heavily encoded. However, they were not entirely erased, peeping through in key phrases about encompassing all diverse "interests" and noting the interconnections between human needs and the "viability of ecosystems." There was an emphasis on making values transparent, in ways that are "equitable and inclusive." Indigenous knowledge was specifically mentioned as contributing to future leadership.

It is also notable that the UN 2018 Report on Water focused almost entirely on promoting "Nature Based Solutions" that, with their implicit remit to work with the realities of local ecosystems, rather than merely imposing "infrastructural violence" upon them (Rodgers and O'Neill 2012), might be said to incorporate some acknowledgement of nonhuman needs in politically palatable form.

\section{PUTTING PRINCIPLES INTO ACTION}

Since the Principles were established, the High Level Panel on Water and its related groups have focused on trying to bring these "top down" ideas to a grassroots level. They are working with an array of small projects, mostly focused on river catchment research. They brought me back into the equation to meet with the researchers involved in these projects and to discuss with them how they might articulate the kinds of cultural values discussed above. Naturally, my major piece of advice has been to work collaboratively with anthropologists and other social scientists and humanities scholars, rather than (as has often happened in river catchment research) asking hydrologists or ecologists to reinvent social science in order to keep things simple. A concurrent aim, therefore, is to encourage scholars from across the academic spectrum to participate in such collaborations.

Key to the success of such activities is the achievement of disciplinary equality so that social scientists and humanities scholars are involved, from the beginning, in the design and implementation of such research and that their findings are fully and equally incorporated into project outputs. This highlights the importance of current debates about facilitating interdisciplinary research, in which it can be seen that the valorization of different disciplines is reflective of the wider values attached to their objects of study. Thus, STEM disciplines promoting technically instrumental and economic solutions tend to have the best access to funding, and to have dominant roles in interdisciplinary research teams, and the social sciences, arts, and humanities are tagged on, often somewhat tokenistically. So, there is important work to do in achieving disciplinary equality in this area.

There is also work to be done in better understanding the multiple professional and political networks that the UN brings together, and how issues are negotiated between them. In a representational system, national or regional interests may be articulated by a politician, a water ecology specialist, an Indigenous leader, 
or a representative from a socially oriented NGO. The confusion of multivocal discussions sometimes seems arduously messy and cumbersome. However, the fluidity of confusion is also organic and creative. Coherent narratives do emerge and generate agreement about action: in this instance, a greater articulation of deeper cultural values, a commitment to shifting the discussion to a grassroots level where changes can be enacted, and a push towards Nature Based Solutions. Making use of the latter, I tried to promote a parallel idea of "Culture Based Solutions." My hope is that the (now widespread) recognition that water infrastructure and management needs to fit the realities of local ecosystems might be translated into a parallel notion, that the use and management of water also needs to cohere with local cultural realities.

\section{CONCLUSION}

How will the UN's initiative to foreground cultural and spiritual values and seek more sustainable engagements with water have a real effect? Thirty years ago, I had an even tinier role working on the Canadian contribution to the Brundtland Report, which set out plans for Our Common Future and promoted the idea that the adoption of sustainable values would save the planet. But since then, as we have seen, anthropogenic impacts on the Earth's ecosystems have worsened dramatically, many societies are struggling with very challenging issues around freshwater, and it is clear that we are heading towards more extreme problems in this critical area.

I would like to be as optimistic about these international efforts as I was in the 1980s, but in the face of dominant ideologies determinedly wedded to growth and competition, the new Principles for Water and the thinking and discussing that they will initiate may be too weak, too little, and too late. We are swimming against the tide. But perhaps, along with the many grassroots countermovements urging real changes, along with emergent ideas about degrowth economics and ecological and social justice, and with the added pressure of sheer terror about water security, maybe-just maybe-there is a tipping point for change that can be reached. The leadership provided by UN High Level Panels and their "sherpas" will be key, as will the diversity of expertise brought to bear on whatever problem is being addressed.

The UN is one of the few organizations that can both provide legitimate leadership and facilitate the international cooperation that is needed. The Principles for Water and the other recommendations of the panel provide a common basis for discussion with policy and decision makers, and we must hope that the combination of top-down and grassroots pressures will encourage them to shift towards more sustainable decisions. I take the view that it is vital to support such efforts. There is surely a critical role for social science and humanities scholars in bringing to the fore the deeper cultural values that are needed to turn societies' current patterns of flow in a more sustainable direction. 


\section{REFERENCES}

Agnoletti, Mauro, and Antonio Santoro. 2015. "Cultural Values and Sustainable Forest Management: The Case of Europe." Journal of Forest Research, 20 (5): 438-44.

Allen, Stewart. 2018. An Ethnography of NGO Practice in India: Utopias of Development. Manchester: Manchester University Press.

Arce, Alberto, and Norman Long, eds. 1999. Anthropology, Development, and Modernities: Exploring Discourses, Counter-Tendencies, and Violence. London: Routledge.

Bangstad, Sindre. 2017. Anthropology of Our Times: An Edited Anthology in Public Anthropology. New York: Palgrave Macmillan.

Berriane, Yasmine. 2017. "Development and Countermovements: Reflections on the Conflicts Arising from the Commodification of Collective Land in Morocco." In Development as a Battlefield, edited by Béatrice Hibou and Irene Bono, International Development Policy Series, no.8, 247-67. Leiden: Brill-Nijhoff.

Bille Larsen, Peter, ed. 2017. World Heritage and Human Rights. London: Earthscan-Routledge.

Brumann, Christoph. 2014. "Shifting Tides of World-Making in the UNESCO World Heritage Convention: Cosmopolitanisms Colliding." Ethnic and Racial Studies 37 (12): 2176-92.

Corsín Jiménez, Alberto. 2007. The Anthropology of Organisations. Abingdon, Oxfordshire: Ashgate.

Crewe, Emma, and Richard Axelby. 2012. Anthropology and Development: Culture, Morality and Politics in a Globalised World. Cambridge: Cambridge University Press.

Escobar, Arturo. 2005. Encountering Development: The Making and Unmaking of the Third World. Princeton: Princeton University Press.

Garsten, Christina, and Anete Nyqvist, eds. 2015. Organisational Anthropology: Doing Ethnography in and among Complex Organizations. London: Pluto Press.

Ghali, Boutros. 1992. An Agenda for Peace: Preventive Diplomacy and Peace Keeping. New York: United Nations Press.

Graeber, David. 2001. Towards an Anthropological Theory of Value: The False Coin of Our Own Dreams. New York: Palgrave Macmillan.

- 2013. "It Is Value that Brings Universes into Being." HAU: Journal of Ethnographic Theory 3 (2): 219-43.

Groenfeldt, David. 2013. Water Ethics: A Values Approach to Solving the Water Crisis. Abingdon: Routledge.

Harmsworth, Garth, Shaun Awatere, and Mahuru Robb. 2016. "Indigenous Māori Values and Perspectives to Inform Freshwater Management in Aotearoa-New Zealand." Ecology and Society 21 (4): 9. http://dx.doi.org/10.5751/ES-08804-210409.

Herzfeld, Michael. 1992. The Social Production of Indifference: Exploring the Symbolic Roots of Western Bureaucracy. Oxford: Berg.

Hobart, Mark, ed. 1993. An Anthropological Critique of Development: The Growth of Ignorance. London: Routledge.

Hoedeman, Oliver, Satoko Kishimoto, Martin Pigeon, and David McDonald. 2013. Remunicipalisation: Bringing Water Back into Public Hands. Amsterdam: Transnational Institute.

Illich, Ivan. 1999. “The Shadow Our Future Throws." New Perspectives Quarterly 16 (2): $14-18$. 
Johnston, Barbara Rose, Lisa Hiwasaki, Irene J. Klaver, Ameyali Ramos-Castillo, and Veronica Strang, eds. 2012. Water, Cultural Diversity \& Global Environmental Change: Emerging Trends, Sustainable Futures? Paris: Springer and UNESCO. http://dx.doi .org/10.1007/978-94-007-1774-9.

Kishimoto, Satoko, Emanuele Lobina, and Olivier Petitjean. 2015. Our Public Water Future: The Global Experience with Remunicipalisation. Amsterdam: Transnational Institute.

Korten, David C. 1990. Getting to the 21st Century: Voluntary Action and the Global Agenda. West Hartford, CT: Kumarian Press.

Lashaw, Amanda, Christian Vannier, and Steven Sampson, eds. 2017. Cultures of Doing Good: Anthropologists and NGOs. Tuscaloosa: University of Alabama Press.

Latour, Bruno. 2005. Reassembling the Social: An Introduction to Actor-Network-Theory. Oxford: Oxford University Press.

Leve, Lauren, and Karim Lamia. 2001. "Privatizing the State: Ethnography of Development, Transnational Capital, and NGOs." Political and Legal Anthropology Review 24 (1): 53-58.

Lewis, David, and David Mosse. 2006. Development Brokers and Translators: The Ethnography of Aid and Agencies. Bloomfield, CT: Kumarian Press.

McMenamin, Dianna, and Mark McMenamin. 1994. Hypersea. New York: Columbia University Press.

Miller, Daniel, Elisabetta Costa, Nell Haynes, Tom McDonald, Razvan Nicolescu, Jolynna Sinanan, Julioano Spyer, Shriram Venkatraman, and Xinyuan Wang. 2016. How the World Changed Social Media. London: UCL Press.

Nader, Laura. 1969. "Up the Anthropologist: Perspectives Gained from Studying Up." In Reinventing Anthropology, edited by Dell Hymes, 285-311. New York: Pantheon.

Nash, June. 1979. "Anthropology of the Multinational Corporations." In New Directions in Political Economy: An Approach from Anthropology, edited by Madeline Barbara Leons and Frances Rothstein, 173-200. Westport, CT: Greenwood Press.

Polanyi, Karl. 1957. The Great Transformation. Boston: Beacon Press.

Robbins, Joel. 2012. "Cultural Values." In A Companion to Moral Anthropology, edited by Didier Fassin, 117-32. West Sussex: Wiley-Blackwell.

Rodgers, Dennis, and Bruce O'Neill. 2012. "Infrastructural Violence: Introduction to the Special Issue." Ethnography 13 (4): 401-12.

Scott, John. 200o. Social Network Analysis: A Handbook. 2nd ed. London: Sage.

Strang, Veronica. 1997. Uncommon Ground: Cultural Landscapes and Environmental Values. Oxford: Berg.

— 2016a. "Justice for All: Inconvenient Truths and Reconciliation in Human-NonHuman Relations." In Major Works in Anthropology: Environmental Anthropology, 2:263-78. London: Taylor and Francis. Reprinted from Routledge International Handbook of Environmental Anthropology, edited by Helen Kopnina and Eleanor Shoreman-Ouimet, Abingdon: Routledge, 2016.

_. 2016b. "Infrastructural Relations: Water, Political Power and the Rise of a New Despotic Regime." In Water Alternatives, special issue: Water, Infrastructure and Political Rule. 9 (2): 292-318.

- 2020. "Materialising the State: The Meaning of Water Infrastructure." In Shifting States, edited by Alison Dundon and Richard Vokes, 43-61. London: Bloomsbury Press. Tomasi, Silvano M. 2017. The Vatican in the Family of Nations: Diplomatic Actions of the Holy See at the UN and Other International Organizations in Geneva. Cambridge: Cambridge University Press. 
Tsing, Anna. 2005. Friction: An Ethnography of Global Connection. Princeton: Princeton University Press.

UNDP (United Nations Development Programme). 2006. "Beyond Scarcity: Power, Poverty and the Global Water Crisis." http://hdr.undp.org/en/content/human-development -report-2006.

United Nations. 2007. "Coping with Water Scarcity: Challenge of the Twenty-First Century." www.un.org/waterforlifedecade/scarcity.shtml.

United Nations High Level Panel on Water. 2018. "Making Every Drop Count: An Agenda for Water Action.” HLPW Outcome Report. https://sustainabledevelopment.un.org /HLPWater.

World Bank. N.d. "Water." www.worldbank.org/en/topic/water/overview/.

WWF (World Wildlife Fund). 2018. "Living Planet Report 2018." Washington, DC: WWF. 